\title{
Pinot noir Crop Estimation Method Allows Growers to Estimate Yields Earlier than Lag Phase
}

\author{
Patricia A. Skinkis ${ }^{1 *}$ and \\ Katherine R. McLaughlin² \\ Cite this article: \\ Skinkis PA and McLaughlin KR. \\ Pinot noir crop estimation method \\ allows growers to estimate yields \\ earlier than lag phase. Catalyst \\ 6:30-37.
}

${ }^{1}$ Department of Horticulture, Oregon State University; and ${ }^{2}$ Department of Statistics, Oregon State University.

${ }^{*}$ Corresponding author (patricia.skinkis@oregonstate.edu)

Manuscript submitted Aug 2021, revised Nov 2021, accepted Dec 2021

This is an open access article distributed under the $\mathrm{CC} B \mathrm{BY}$ license (https://creativecommons. org/licenses/by/4.0/).

By downloading and/or receiving this article, you agree to the Disclaimer of Warranties and Liability. The full statement of the Disclaimers is available at https://www.asevcatalyst.org/ content/proprietary-rights-noticecatalyst. If you do not agree to the Disclaimers, do not download and/ or accept this article.

doi: 10.5344/catalyst.2021.21005

\section{Summary}

Goals: Winegrape growers must estimate yields to prepare for harvest operations and winery processing. Standard practice requires waiting until the lag phase of berry development, which is late for making decisions related to crop thinning, fruit sales, winery inventory, and ordering wine production supplies. Because producers desire improved methods for accurate crop estimation, we evaluated the following questions over six growing seasons for Oregon Vitis vinifera Pinot noir: 1) When does lag phase occur? 2) What cluster weight increase factor should be used with lag phase crop estimation? and 3) Can crop estimation be conducted earlier in the growing season?

\section{Key Findings:}

- The Pinot noir berry development curve was consistent across six years when based on days post-full bloom ( $50 \%$ capfall).

- The mid-point of lag phase, the most common time to estimate crop yields, was at 55 days post $50 \%$ capfall. Lag phase duration was 12 days. Mean cluster weight increase factor during the entire lag phase over the six-year period was 2.1.

- Cluster weight increase factor equations were developed based on post-budbreak and bloom thermal times and day counts to allow growers flexibility in timing of crop estimation.

Impact and Significance: Data was used to improve upon manual lag phase crop estimation protocols commonly used by winegrape producers, including methods to identify berry lag phase occurrence and developing equations for cluster weight increase factors based on berry development. These modifications may improve the accuracy of manual yield estimates and allow growers to obtain yield estimates earlier in the growing season than previously allowed by standard practice. This methodology may be useful in testing increase factors for other grape cultivars.

Key words: berry weight, grapevine yield, phenology, yield estimation, yield prediction

\section{Overview}

Yield estimation is important, as it allows winegrape growers to predetermine harvest yields in anticipation of winery processing. Early yield estimates help producers make fruit thinning decisions, manage vine health, allocate winery space, purchase goods and supplies, and determine sales. Crop estimation may be conducted as early as the dormant bud stage by quantifying floral primordia in winter preceding the crop year, ${ }^{1}$ but prebloom and post-fruit set inflorescence/cluster counts are used more commonly. ${ }^{2,3,4}$ The Oregon winegrape industry conducts yield estimation at the lag phase of berry development (stage II), and cluster thinning ensues thereafter. This process occurs in August and poses a problem for wineries, as they must purchase wine production supplies well in advance of a September or October harvest. Vineyards and wineries 
expend significant time and labor on yield forecasting to guide cluster thinning decisions. Viticulture interns or part time/seasonal workers typically collect these data.

Efficient, non-destructive image assessment methods are being developed for precision agriculture-aided vineyard yield estimation. ${ }^{5,6,7,8}$ However, many smaller producers cannot readily adopt precision agriculture technologies to estimate yield due to lack of economy, access, or technical training, even though lower-cost options and remote sensing-aided manual methods are under development. ${ }^{5,6,9}$ Furthermore, many precision agriculture techniques to improve crop estimation efficiency and throughput are not yet commercially available to growers and are just now starting to be developed through service providers. In the meantime, both large and small producers need improved methods for manual crop estimation to provide more accurate estimates for production and process planning.

The majority of the winegrape industry currently uses straightforward, manual yield estimation methods that use post-fruit set cluster counts and weights obtained at lag phase or historic harvest cluster weights. ${ }^{4}$ Yield estimation requires manually counting clusters per vine and gathering cluster weights from representative vines in vineyard blocks during lag phase and accounting for missing or under-producing vines. Oregon producers use a method that requires taking cluster weight measures at mid-lag phase, which is defined as 55 days after bloom initiation, and applying an increase factor of two. ${ }^{2}$ This methodology is used across cultivars in Oregon and has been adopted by other U.S. winegrape production regions and cultivars. ${ }^{1,3,10,11}$ This Pinot noir-based crop estimation method has two issues in practice. First, it is difficult to identify when lag phase occurs since it is not visibly discernable, and many producers question the accuracy of number of days postbloom to determine lag phase. Second, it is unclear what increase factor should be used to calculate yield from lag phase cluster count and weight data. Knowing when lag phase occurs is critical because it is the time at which berry size (weight and volume) plateaus, ${ }^{12,13,14}$ which offers a longer timeframe to gather cluster weight data than other points in the season. An increase factor of two has historically been applied to cluster weights at this stage, as berries are approximately half of their final weight at harvest. Lag phase, unlike other phenological stages, is nearly impossible to determine visually and has no phenological stage assigned in grapevine phenology scales. ${ }^{15,16}$ Therefore, we need other methods to identify when vineyards reach lag phase or determine another time at which to accurately estimate yields. Furthermore, knowing increase factors for cluster weights measured at different points in the growing season would allow more flexibility in estimation timing.

We conducted a multi-year study to determine when lag phase occurs in Pinot noir and which cluster weight increase factors to use for yield estimation. The goal was to improve upon the industry's standard crop estimation methods.

\section{Major Observations and Interpretations}

We originally set out to identify when lag phase occurred in Pinot noir berry development so that growers could better predict lag phase for use in their current yield estimation protocols. We measured Pinot noir cluster morphology up to twice weekly from post-fruit set to harvest over six growing seasons. We recorded day count and thermal time (growing degree days [GDDs] base $10^{\circ} \mathrm{C}$ and $50^{\circ} \mathrm{F}, \mathrm{GDD}_{10}$ and $\mathrm{GDD}_{50}$ ) post-budbreak and post-50\% capfall (full bloom) and used this to compare berry growth data across years. The region experienced one of the coolest seasons in Oregon wine production history in 2011 (1 April to 31 Oct accumulated only $1161 \mathrm{GDD}_{10}$, or $2090 \mathrm{GDD}_{50}$ ) and one of the warmest seasons in 2015 (1 April to 31 Oct accumulated 1632 $\mathrm{GDD}_{10}$, or $2938 \mathrm{GDD}_{50}$ ) (Figure 1).

Berry mass followed a double-sigmoidal growth curve as described by others. ${ }^{12,13,14,17}$ There was consistency in berry development based on day count following the date of $50 \%$ capfall (Figure 2). Despite annual weather variability, there was consistency in GDD accumulation between key phenological stages, with the budbreak to bloom period having more consistency (coefficient of variation, $\mathrm{CV}=5 \%$ ) than the bloom to veraison period ( $\mathrm{CV}=8 \%$ ) (Figure 1 ), as noted by others. ${ }^{12}$ The midpoint of lag phase occurred at $556 \mathrm{GDD}_{10}$ $\left(1000 \mathrm{GDD}_{50}\right.$ ) post $50 \%$ capfall, based on the six year mean (Table 1), which was similar to observations in eastern U.S. winegrape production regions. ${ }^{3}$ Likewise, other grape phenology models showed strong consistent relationships between thermal time and key phenology stages. ${ }^{18,19,20,21,22,23}$

Likewise, the number of days from $50 \%$ capfall to mid-lag phase was relatively consistent at $\sim 55$ days (Table 1). Lag phase started $\sim 49$ days and ended by $\sim 60$ days post- $50 \%$ capfall, with a mean duration of 12 days. The 2015 growing season was a climatic anomaly with budbreak occurring three weeks early and high postbloom temperatures that resulted in earlier lag phase onset. However, the end of lag phase aligned with that of other years at $\sim 60$ days (Table 1 ). Berry weight reached 
its maximum mass at 81 days post- $50 \%$ capfall (standard deviation $[\mathrm{SD}]=3, \mathrm{CV}=3 \%$ ). This was the point at which the berries reached 18 Brix ( $S D=1, C V=3 \%$ ), but Brix ranged from 17.6 to 19.0 , depending on the year.

Seed hardness as a lag phase indicator. We also tested berry seed hardness during each sample date in 2014 to 2016 to determine the point at which the majority of seed tips were hard, an indicator of the end of berry development phase I. ${ }^{24}$ This has been a common method used by growers to identify lag phase. The first hard seeds were observed at $\sim 32$ days post- $50 \%$ capfall. The number of hard seeds increased rapidly from 40 to 60 days post- $50 \%$ capfall, and $100 \%$ of seeds were hard by $\sim 61$ days post- $50 \%$ capfall each year.

Rachis weight. We monitored rachis weight development each season because of its contribution to yield loss in estimating yields for mechanical harvest. The rachis comprised $6.3 \%$ of the cluster weight during lag phase $(\mathrm{SD}=0.5, \mathrm{CV}=8 \%)$ and reached its maximum at $\sim 80$ days post- $50 \%$ capfall at $4.3 \%$ of the cluster weight (SD $=0.3, \mathrm{CV}=7 \%$ ).

Cluster weight increase factors. The second objective of this work was to identify cluster weight increase factors to be used for yield estimation calculations. An increase factor, or multiplication factor, is used in the crop estimation calculation to estimate the cluster weight at harvest. An increase factor of two has traditionally been used when cluster weights are measured at lag phase, as that is the point in development when the berry is half the size that it will be by harvest. Initially, growers were most concerned about the accuracy of the increase factor to use at lag phase since that is the standard time to conduct estimations. Increase factors were determined in our study for each sample date and plotted by day count and thermal time $\left(\mathrm{GDD}_{10}\right.$ and $\left.\mathrm{GDD}_{50}\right)$ post-budbreak and post- $50 \%$ capfall. There was consistency in the increase factors for both day count and thermal time (Figure 3). Increase factors declined rapidly in the weeks following fruit set and a slower rate of change began $\sim 30$ days or

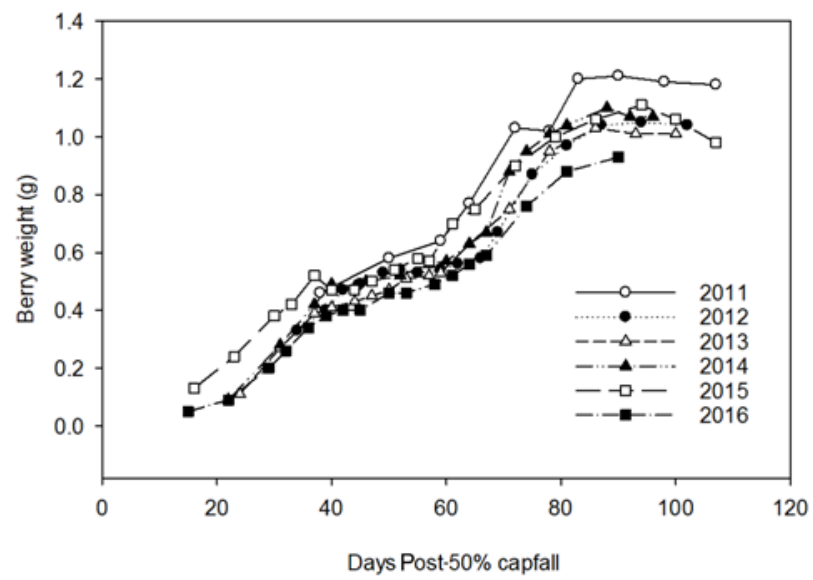

Figure 2 Mean berry mass measured from post-fruit set to harvest during six growing seasons (2011 to 2016) from a commercial Pinot noir vineyard in Dayton, OR.

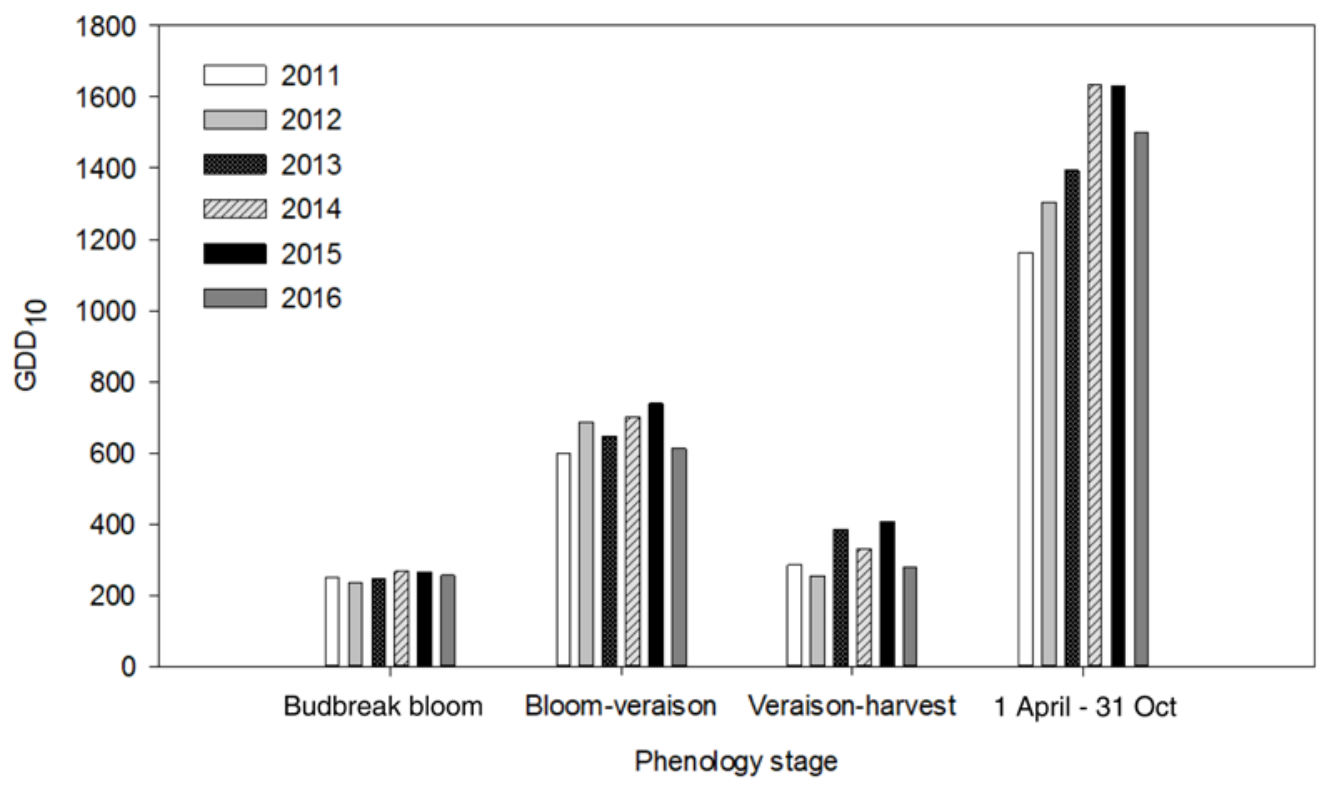

Figure 1 Heat unit accumulation by Pinot noir phenological stage of development in Dayton, OR. Bloom is defined as $50 \%$ capfall, and veraison was defined as the start of color development in at least $5 \%$ of berries on $50 \%$ of clusters. Heat units are shown as $\mathrm{GDD}_{10}$, or growing degree days with a minimum temperature threshold of $10^{\circ} \mathrm{C}$; data were calculated using daily temperatures $(\mathrm{T})$ obtained from a regional weather station (Aurora, OR; ARAO, Agrimet, https://www.usbr.gov/pn/agrimet/) using the equation $\left(\mathrm{T}_{\max }+\mathrm{T}_{\min }\right) / 2-10^{\circ} \mathrm{C}$. 
$\sim 277 \mathrm{GDD}_{10}$ post-50\% capfall. The increase factor during lag phase was 2.1, based on the six-year mean (Table 2 ). Clusters reached maximum weight at $\sim 80$ days post$50 \%$ capfall, when the increase factor was 1.0 (Figure 3 ), plateauing at the same time as berry mass (Figure 2 ), at $\sim 18$ Brix.

Power curve models fit to increase factor versus day count and thermal time ( $\mathrm{GDD}_{10}$ and $\left.\mathrm{GDD}_{50}\right)$ post-budbreak and post- $50 \%$ capfall approximated the curvilinear trends well, with root mean square errors (RMSE) under 0.8 on the scale of increase factor for all models (Figure 3 ). The models using duration post-50\% capfall had greater accuracy (lower RMSE) than those using duration post-budbreak. There was a very rapid change in increase factor at $<30$ days post- $50 \%$ capfall, making it challenging to model this early stage of berry development.

We tested the increase factor equations for day-count post-50\% capfall in 2020, using a different commercial Pinot noir vineyard in the north Willamette Valley (Pommard clone on 101-14 rootstock). The increase factors aligned well, with $100 \%$ agreement at 30 to 35 days post$50 \%$ capfall and many other time points at $90 \%$ agreement (Figure 4). Measures before 30 days postbloom were not as accurate, due to less data on this early stage of berry development to inform the model and the rapid change in berry size at this time. The 2020 season had poor fruit set with low berry number per cluster and significant berry size variation with normal-sized berries and significantly smaller berries within the same cluster (otherwise known as "hens and chicks"). However, the increase factor equation worked well to estimate increase factors in 2020. We anticipate that increase factors would agree better in clusters with good fruit set in a more typical year. The equations that result from our models (Table 3) provide a basis to predict future harvests when using data collected by growers.

\section{Broader Impact}

Identifying lag phase was the primary concern of the industry at the outset of this research, as it was the point at which they would apply their standard crop estimation procedures. The common identifiers of lag phase are 1) number of days postbloom and 2) the point at which seeds reach $75 \%$ hard seed tips. ${ }^{2}$ Our study confirmed that the day count was consistent across six growing seasons and fell within the range described previously for the region. ${ }^{2}$ However, our work provides clarification regarding day count and thermal time accumulated after full bloom ( $50 \%$ capfall) and budbreak. The clarification of bloom time was important, as Oregon vineyards can experience long bloom periods that range from days in warm years to a week or more in cool years. Despite differences in weather between years, day count and thermal time were relatively consistent from bloom to lag phase and veraison, confirming observations and grapevine growth models developed by others. ${ }^{18,20,21,23}$

We carefully and systematically measured seed hardness during three growing seasons to determine whether a specific percentage of seed hardness could identify lag phase. It was difficult to pinpoint a specific seed hardness percentage that identified lag phase for crop estimation purposes due to the rapidly changing seed hardness levels during 40 to 60 days postbloom. Since it is difficult to test seed hardness objectively or scale up to larger acreage sampling, it is not recommended for growers to use this as a means to identify lag phase timing. Likewise, no phenology studies have used seed hardness as a marker of phenological advancement to our knowledge, likely due to the laborious nature of this evaluation.

A cluster weight increase factor of two at lag phase is commonly prescribed in winegrape crop estimation outreach publications $\mathrm{s}^{1,3,10}$ and conducted in practice by many growers. This study shows that using a cluster weight increase factor of two is not advised when conducting crop estimation at the phenology-defined lag phase occurring at $\sim 55$ days post $-50 \%$ capfall. While berries may increase in weight by a factor of two from lag phase to

Table 1 The timing of lag phase occurrence during six growing seasons in a commercial Pinot noir vineyard in Dayton, OR. GDD, growing degree days.

\begin{tabular}{|c|c|c|c|c|c|c|}
\hline Year & $\begin{array}{c}\text { Start } \\
(\text { DPFB })^{\mathrm{a}}\end{array}$ & $\begin{array}{l}\text { Mid-lag } \\
\text { phase } \\
\text { (DPFB) }\end{array}$ & $\begin{array}{l}\text { Finish } \\
\text { (DPFB) }\end{array}$ & $\begin{array}{c}\text { Duration } \\
\text { of lag } \\
\text { phase } \\
\text { (days) }\end{array}$ & $\begin{array}{l}\text { Mid- } \\
\text { lag } \\
\text { phase } \\
\text { heat } \\
\text { units } \\
\text { GDD }_{10}{ }^{b}\end{array}$ & $\begin{array}{c}\text { Mid-lag } \\
\text { phase } \\
\text { heat } \\
\text { units } \\
\text { GDD }_{50}{ }^{b}\end{array}$ \\
\hline 2011 & 50 & 55 & 59 & 9 & 536 & 964 \\
\hline 2012 & 49 & 54 & 59 & 10 & 554 & 997 \\
\hline 2013 & 53 & 56 & 59 & 6 & 546 & 982 \\
\hline 2014 & 52 & 56 & 60 & 8 & 582 & 1047 \\
\hline 2015 & 37 & 51 & 61 & 24 & 593 & 1068 \\
\hline 2016 & 50 & 58 & 67 & 17 & 525 & 945 \\
\hline Mean & 49 & 55 & 61 & 12 & 556 & 1001 \\
\hline $\mathrm{SD}^{\mathrm{c}}$ & 6 & 2 & 3 & 7 & 27 & 48 \\
\hline$C V \%^{d}$ & 12 & 4 & 5 & 55 & 5 & 5 \\
\hline
\end{tabular}

aDays post- $50 \%$ capfall.

${ }^{b}$ GDD post-full bloom, defined as $50 \%$ capfall, calculated by daily temperatures $(T)$ obtained from a regional weather station (ARAO, Agrimet, https://www.usbr.gov/pn/agrimet/) using the equation $\left(\mathrm{T}_{\max }+\mathrm{T}_{\min }\right) / 2-10^{\circ} \mathrm{C}$ or $\left(\mathrm{T}_{\max }+\mathrm{T}_{\min }\right) / 2-50^{\circ} \mathrm{F}$.

'Standard deviation of the mean.

${ }^{\mathrm{d}}$ Coefficient of variation. 
harvest, the cluster weight may not. Furthermore, data in this study were collected on healthy, intact clusters at harvest that were not subject to extended hang-time and thus were not affected by desiccation. Extended late-season hang-time should be factored into crop estimation equations, as desiccation will affect harvest cluster weight. Conversely, regions that deal with late season precipitation may have berry weight gain due to water, or loss due to rots. Changes in berry mass due to such factors are hard to predict and make crop estimation difficult under certain climatic conditions. However, crop estimation methods described here may still prove valuable for providing a baseline expectation of crop level under those conditions.

Although earlier estimates are ideal for process planning, cluster weights measured once berries reach the berry weight plateau at or after 81 days post- $50 \%$ capfall allow the greatest yield accuracy preharvest, as long as proper cluster sampling is used and berries are not subject to significant desiccation or rots. Since many Oregon Pinot noir producers harvest fruit for table wines at 110 days postbloom, this method provides an accurate yield forecast nearly 30 days prior to harvest.

We shared the cluster weight increase factors (Table 3 and Figure 3) with growers during the 2018 to 2020 growing seasons to learn how well they estimated the crop yields compared to standard methods. The growers reported improved crop estimation accuracy, with greater accuracy in crop estimates in the warm, dry year (2018) than in a cooler, wetter year (2019). Preharvest rains in 2019 and wildfire smoke in 2020 complicated crop estimation comparisons for many growers. As a result of this
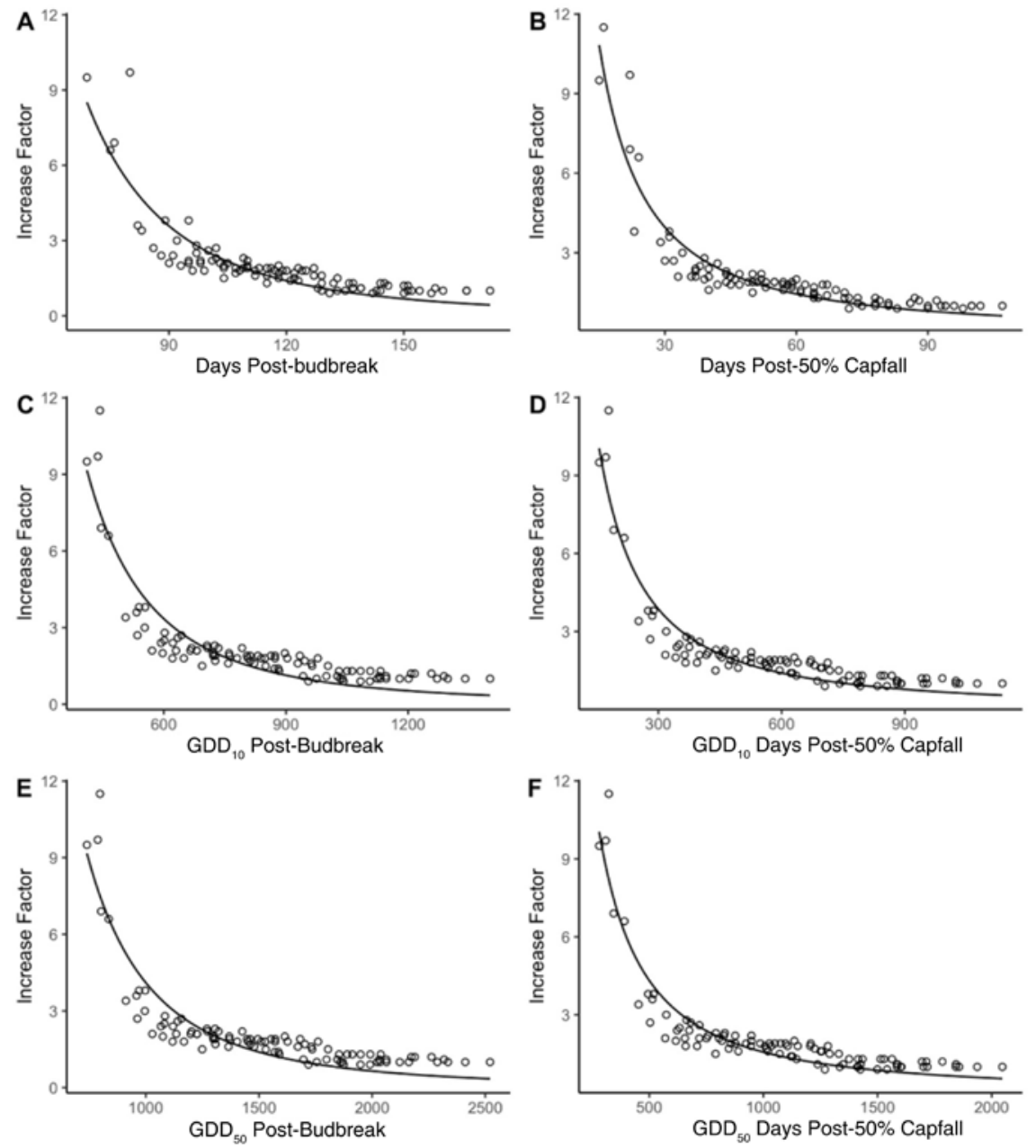

Figure 3 Increase factors of Pinot noir clusters, determined by comparing cluster weights during development to final cluster weight at harvest during six growing seasons (2011 to 2016) in a commercial vineyard in Dayton, OR. Relationships of increase factors are shown for A) days post-budbreak ( $y=8518472 \mathrm{x}^{-3.26}$, root mean square error $\left.[\mathrm{RMSE}]=0.7142\right)$; $\left.\mathbf{B}\right)$ days post-50\% capfall $\left(\mathrm{y}=551.61 \mathrm{x}^{-1.45}, \mathrm{RMSE}=0.6309\right)$; C) growing degree days (GDD) base $10^{\circ} \mathrm{C}$ post-budbreak $\left(y=84609124 x^{-2.66}, R M S E=0.7794\right)$; $\left.D\right)$ GDDs base $10^{\circ} \mathrm{C}$ post-50\% capfall $(y=16216.31$ $\left.\mathrm{x}^{-1.46}, \mathrm{RMSE}=0.6126\right)$; $\left.\mathrm{E}\right)$ GDDs base $50^{\circ} \mathrm{F}$ post-budbreak $\left(\mathrm{y}=402640001 \mathrm{x}^{-2.66}\right.$, RMSE $\left.=0.7785\right)$; and $\left.\mathrm{F}\right)$ GDDs base $50^{\circ} \mathrm{F}$ post-50\% capfall $\left(y=38007.28 x^{-1.46}\right.$, RMSE $\left.=0.6132\right)$. 
research adoption, growers pay more attention to full bloom timing, focusing on the $50 \%$ capfall date. Because identifying $50 \%$ capfall in vineyards can be difficult and subjective, we recommended that growers record the bloom start and finish dates, estimating $50 \%$ capfall as the mid-point in those dates. Others who trained their phenology scouts to observe $\sim 50 \%$ capfall were able to note the exact date that this point was reached. Our study results also enabled growers to apply the increase factor equations based on heat units and days post-budbreak, in the event that they missed detailed bloom dates. In theory, documenting $50 \%$ budbreak should be easier for growers to rate and record due to fewer tasks needing their attention in the vineyard than at bloom. However, many growers already focus on bloom dates due to the importance of applying fungicides to prevent powdery mildew at this important stage.

This work helps Pinot noir growers estimate crop earlier in the growing season than allowed by previous industry standard practice. Because this work focused on only one cultivar, application to other cultivars in the region or across regions is unknown. While many U.S. wine regions use the same industry standard method as Oregon, ${ }^{1,3,10,11}$ which was based on Pinot noir, ${ }^{2}$ it is recommended that producers develop their own historic cluster weight data based on sample timing and harvest to generate the most accurate estimates. Furthermore, accuracy of crop estimates still requires attention to sound vineyard data collection, including proper cluster weight sampling procedures to ensure representative sampling and cluster and vine counts per block. Process improvements to crop estimation, such as those provided here, are valuable to producers until more efficient means of mechanical estimation are commercially available and feasible for growers at all production scales.

\section{Experimental Design}

Sampling method. We monitored grape berry development during six seasons (2011 to 2016) to improve yield estimation methods. Whole clusters were collected from a commercial vineyard block located in the Dundee Hills American Viticultural Area (AVA) in Dayton, Oregon. The vineyard was planted in 1998 to Vitis vinifera cv. Pinot noir (Dijon clone 115) grafted onto 101-14 rootstock with 2.1 $\mathrm{m}$ row spacing and $1.5 \mathrm{~m}$ vine spacing and north-south row orientation. Vines were cane-pruned to a bilateral Guyot system with vertical shoot-positioning and managed in-season according to commercial standard practice for canopy management and disease control. However, cluster thinning did not occur in this vineyard to avoid cluster size or yield manipulation. The vineyard was dry- farmed during the years of this study, although it was equipped with drip irrigation for application as needed. The fruit sampling area was $\sim 0.4$ ha and 50 whole clusters were collected randomly from five rows within the block, collecting 10 clusters per row, ensuring that only one cluster was sampled per vine and alternating eastern and western sides of the canopy to avoid cluster exposure effects. Samples were collected weekly for most of the season, post-fruit set through harvest. However, we switched to twice-weekly sampling leading up to and

Table 2 Lag phase and harvest cluster weights and resulting increase factors during the lag phase of Pinot noir across six growing seasons in Dayton, OR.

\begin{tabular}{lccc}
\hline Year & $\begin{array}{c}\text { Lag phase } \\
\text { cluster } \\
\text { wt (g) }\end{array}$ & $\begin{array}{c}\text { Harvest } \\
\text { cluster } \\
\text { wt (g) }\end{array}$ & $\begin{array}{c}\text { b } \\
\text { Cluster weight } \\
\text { increase factor }^{\mathrm{b}}\end{array}$ \\
\hline 2011 & $90.3( \pm 26.7)$ & $161.3( \pm 43.7)$ & $2.0( \pm 0.08)$ \\
2012 & $57.8( \pm 21.1)$ & $110.0( \pm 32.3)$ & $2.2( \pm 0.10)$ \\
2013 & $50.3( \pm 17.8)$ & $92.8( \pm 33.1)$ & $2.3( \pm 0.11)$ \\
2014 & $88.7( \pm 29.9)$ & $180.4( \pm 47.6)$ & $2.3( \pm 0.14)$ \\
2015 & $95.7( \pm 38.0)$ & $175.5( \pm 60.8)$ & $2.1( \pm 0.31)$ \\
2016 & $73.2( \pm 30.8)$ & $114.3( \pm 45.8)$ & $1.9( \pm 0.20)$ \\
Six year & 76 & 139 & 2.1 \\
mean & 19 & 38 & 0.16 \\
SD $^{d}$ & 25 & 27 & 8 \\
CV\% $^{\text {e }}$ & & & \\
\hline
\end{tabular}

${ }^{a}$ Mean cluster weight during lag phase for that year with standard deviations in parentheses.

${ }^{\mathrm{b}}$ Mean cluster weight at harvest with standard deviation in parentheses.

${ }^{\circ}$ Cluster weight increase factor determined by dividing the mean harvest cluster weight with the mean lag phase cluster weights during the range of dates that year.

dStandard deviation of the mean.

${ }^{\mathrm{e}}$ Coefficient of variation.

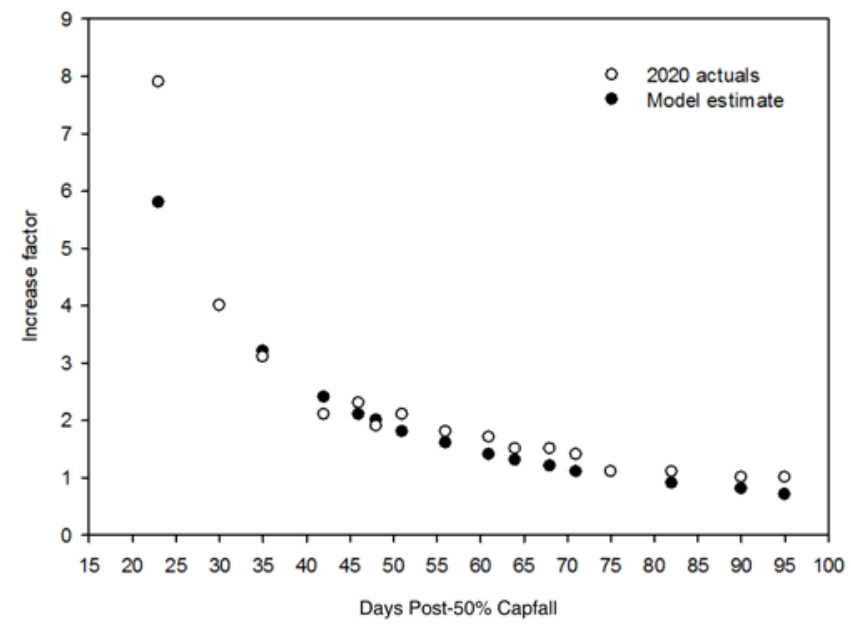

Figure 4 Comparison of cluster weight increase factors using the model increase factor at day count post- $50 \%$ capfall $\left(y=551.61 x^{-1.45}\right)$ and the actual Pinot noir cluster size increase factor measured in a commercial Pinot noir Pommard vineyard in Newberg, OR during the 2020 growing season. 
just following lag phase to document the plateau (lag) in berry weight in 2012 to 2016 . We placed the clusters in a cooler and brought them to the lab for measurements or took weights and measures immediately on-site. Clusters were refrigerated in a cold room at $4^{\circ} \mathrm{C}$ until analysis and all clusters were processed within $24 \mathrm{hrs}$ of sampling to avoid desiccation.

Cluster measures. We measured individual cluster weight, removed and counted berries per cluster, measured rachis weight and length (from first branch of the rachis to the tip), and calculated berry weight ((whole cluster weight - rachis weight)/ berry count). We noted the percentage of colored berries in each cluster once veraison began. Cluster weight increase factors were determined at the end of each season by dividing the mean harvest cluster weight by the weight of each cluster measured at each sample date. The mean increase factor for each sample date was calculated from all individual increase factors on that date. These increase factors were analyzed relative to day count key phenological timing (post-budbreak or post-50\% capfall) and thermal time of the sample date to understand whether relationships emerged over multiple growing seasons.

Seed hardness. We tested seed hardness on 100 randomly selected berries per sample in 2014 to 2016 to determine whether seed hardness could determine the occurrence of lag phase, as it has been used by industry to identify lag phase. One trained person conducted all seed hardness tests in a given season to avoid worker variability. He/she placed the berries on a petri dish and cut through the berry with a sharp scalpel at the equator, perpendicular to the pedicel. If the evaluator could not cut through the seed with a single cut, the seed was consid-

Table 3 Equations for cluster weight increase factors determined by comparing Pinot noir harvest cluster weights to cluster weights during development over six growing seasons (2011 to 2016) in a commercial vineyard in Dayton, OR. Relationships of cluster weight increase factors are shown for day count and thermal time from budbreak and $50 \%$ capfall. GDD, growing degree days.

\begin{tabular}{llll}
\hline Period & $\begin{array}{c}\text { Time } \\
\text { parameter }\end{array}$ & \multicolumn{1}{c}{ Equation } & RMSE $^{\mathrm{a}}$ \\
\hline Post-budbreak & Day count & $\mathrm{y}=8518472 \mathrm{x}^{-3.26}$ & 0.7142 \\
& $\mathrm{GDD}_{10} \mathrm{~b}$ & $\mathrm{y}=84609124 \mathrm{x}^{-2.66}$ & 0.7794 \\
& $\mathrm{GDD}_{50} \mathrm{~b}$ & $\mathrm{y}=402640001 \mathrm{x}^{-2.66}$ & 0.7785 \\
Post-50\% & Day count & $\mathrm{y}=551.61 \mathrm{x}^{-1.45}$ & 0.6309 \\
capfall & $\mathrm{GDD}_{10}$ & $\mathrm{y}=16216.31 \mathrm{x}^{-1.46}$ & 0.6126 \\
& $\mathrm{GDD}_{50}$ & $\mathrm{y}=38007.28 \mathrm{x}^{-1.46}$ & 0.6132 \\
\hline
\end{tabular}

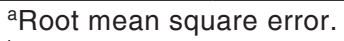

bGDD post-full bloom, calculated by daily temperatures $(T)$ obtained from a regional weather station (ARAO, Agrimet, https://www.usbr.gov/pn/agrimet/) using the equation $\left(T_{\max }+\right.$ $\left.\mathrm{T}_{\min }\right) / 2-10^{\circ} \mathrm{C}$ and $\left(\mathrm{T}_{\max }+\mathrm{T}_{\min }\right) / 2-50^{\circ} \mathrm{F}$. ered hard. The number of hard seeds and total number of seeds from 100 berries were recorded to determine the percentage of hard seeds at each sample date.

Fruit ripeness. Fruit ripeness parameters were measured to determine whether they could be used as a marker of lag phase for crop estimation. We began monitoring this earlier each year of the trial, with our earliest sampling of Brix occurring at 30 days post- $50 \%$ capfall. All berries from each sample were mixed and separated into a minimum of three subsamples, pressed for juice, and measured for total soluble solids (Brix), $\mathrm{pH}$, and titratable acidity (TA). Total soluble solids were measured using a digital refractometer (Sper Scientific Ltd.) and began once berries reached the pea-size stage (BBCH 75). The $\mathrm{pH}$ and TA of juice was measured at each postveraison sampling period in most years $(2011,2014,2015$, and 2016). The $\mathrm{pH}$ was measured using a $\mathrm{pH}$ meter (Accumet AB15, Fisher Scientific) and TA was determined by titrating with $0.1 \mathrm{~N} \mathrm{NaOH}$ to an endpoint of $\mathrm{pH}=8.2 .^{25}$

The same procedures as noted above were conducted on 60 Pinot noir clusters per sampling date in 2020 to test the model against increase factors calculated from that vineyard. The samples were collected from a commercial vineyard in Newberg, OR. The vines were planted in 2008 to the Pommard clone of Pinot noir grafted to $101-14$ rootstock at $1.5 \mathrm{~m}$ vine spacing and $1.95 \mathrm{~m}$ row spacing on a north-south slope. Vines were trained to a bilateral Guyot system with vertical shoot-positioning and were managed using standard disease and canopy management practices for the region. The vineyard was dry-farmed.

Phenology and weather data. We recorded vine phenology stages during each growing season using the extended BBCH scale. ${ }^{16}$ This was critical to determine berry and cluster size development relative to growth stages. Days were counted post-budbreak (DPBB) and 50\% capfall (DP50B) to standardize berry development data comparisons across seasons and to determine whether day count could predict lag phase. Daily temperature data were obtained from the publicly-available regional weather station (Aurora, OR, AgriMet, US Bureau of Reclamation) and used to calculate GDDs $\left(\mathrm{GDD}_{10}\right)$ for each day using the simple average method $\left(\mathrm{T}_{\max }+\mathrm{T}_{\min }\right) / 2$ $-10^{\circ} \mathrm{C}$. The $\mathrm{GDD}_{10}$ summation between key phenological stages was compared across years to determine whether GDD ranges could predict lag phase occurrence. We also present heat unit data in $\mathrm{GDD}_{50}$ for reader convenience, which reflects the simple average method $\left(\mathrm{T}_{\max }+\mathrm{T}_{\min }\right) / 2$ - $50^{\circ} \mathrm{F}$ which can also be determined by $\left(9 / 5^{*} \mathrm{GDD}_{10}\right)$.

Statistics. We analyzed data using descriptive statistics (means, SD, standard errors, and CV). Plots of cluster 
weight increase factor versus days post-budbreak, days post- $50 \%$ capfall, $\mathrm{GDD}_{10}$ post-budbreak, and $\mathrm{GDD}_{10}$ post$50 \%$ capfall each revealed a curvilinear relationship, so a power curve was fit to each using nonlinear least squares. Although the power curve slightly overestimated the increase factor for moderately small values of the independent variable, and slightly underestimated the increase factor for large values of the dependent variable, it was selected over a more complex polynomial or piecewise function because it produced a simple equation that growers could interpret and implement with their own data. Model fitting was performed using the nls function in the R statistical programming language (Version 3.6.1) (R Core Team 2019, https://www.R-project.org/). Model fit was assessed using the RMSE, which has the same units as increase factor and can be thought of as how far away a typical observation is from the estimated model value for increase factor. Smaller values of RMSE (close to 0 ) indicate better model fit. The resulting power curve models are presented (Table 3 and Figure 3) and may aid growers in predicting the yield of future harvests.

\section{References and Endnotes}

1. Komm B and Moyer MM. 2015. Vineyard yield estimation. Washington State University Extension. EM086E. https:// pubs.extension.wsu.edu/vineyard-yield-estimation.

2. Price S. 1992. Predicting yield in Oregon vineyards. In Oregon Winegrape Grower's Guide. 4th ed. Casteel T (ed.). Oregon Winegrowers Association, Portland, OR.

3. Sabbatini P, Dami I and Howell GS. 2012. Predicting harvest yield in juice and wine grape vineyards. Michigan State University Extension Bulletin 3186. http://msue.anr.msu. edu/uploads/resources/pdfs/Predicting_Harvest_Yield_ in_Juice_and_Wine_Grape_Vineyards_\%28E3186\%29.pdf.

4. Wolpert JA and Vilas EP. 1992. Estimating vineyard yields: Introduction to a simple, two-step method. Am J Enol Vitic 43:384-388.

5. Di Gennaro SF, Toscano P, Cinat P, Berton A and Matese A. 2019. A low-cost and unsupervised image recognition methodology for yield estimation in a vineyard. Front Plant Sci 10:559.

6. Liu S, Cossell S, Tang J, Dunn G and Whitty M. 2017. A computer vision system for early stage grape yield estimation based on shoot detection. Comput Electron Agric 137:88-101.

7. Millan B, Aquino A, Diago MP and Tardaguila J. 2016. Image analysis-based modelling for flower number estimation in grapevine. J Sci Food Agric 97:784-792.

8. Nuske S, Wilshusen K, Achar S, Yoder L, Narasimhan S and Singh S. 2014. Automated visual yield estimation in vineyards. J Field Robot 31:837-860.

9. Sun L et al. 2017. Daily mapping of $30 \mathrm{~m} \mathrm{LAI}$ and NDVI for grape yield prediction in California vineyards. Remote Sens 9:317.
10. Dami I and Sabbatini P. 2012. Crop estimation of grapes. The Ohio State University. Factsheet HYG-1434-11. https:// ohioline.osu.edu/factsheet/HYG-1434-11.

11. Wolf T. 2015. Crop Prediction. In North Carolina Wine Grape Grower's Guide. Poling EB (ed). North Carolina Cooperative Extension Service. https://content.ces.ncsu. edu/north-carolina-winegrape-growers-guide/chapter12-crop-prediction.

12. Coombe BG. 1992. Research on development and ripening of the grape berry. Am J Enol Vitic 43:101-110.

13. Coombe BG and McCarthy MG. 2008. Dynamics of grape berry growth and physiology of ripening. Aust J Grape Wine Res 6:131-135.

14. Letchov G and Roychev V. 2017. Growth kinetics of grape berry density (Vitis vinifera L. 'Black Corinth'). Vitis 56:155-159.

15. Coombe BG. 1995. Growth stages of the grapevine: Adoption of a system for identifying grapevine growth stages. Aust J Grape Wine Res 1:104-110.

16. Lorenz DH, Eichhorn KW, Bleiholder H, Klose R, Meier U and Weber E. 1995. Growth stages of the grapevine: Phenological growth stages of the grapevine (Vitis vinifera L. spp. vinifera): Codes and descriptions according to the extended BBCH scale. Aust J Grape Wine Res 1:100-103.

17. Cohen SD, Tarara JM, Gambetta GA, Matthews MA and Kennedy JA. 2012. Impact of diurnal temperature variation on grape berry development, proanthocyanidin accumulation, and the expression of flavonoid pathway genes. J Exp Bot 63:2655-2665.

18. Bindi M, Miglietta F, Gozzini B, Orlandini S and Seghi L. 1997. A simple model for simulation of growth and development in grapevine (Vitis vinifera L.). 1 Model description. Vitis 36:67-71.

19. Fernández-González M, Rodríguez-Rajo FJ, Escuredo 0 and Aira MJ. 2013. Influence of thermal requirement in the aerobiological and phenological behavior of two grapevine varieties. Aerobiologia 29:523-535.

20. McIntyre GN, Lider LA and Ferrari NL. 1982. The chronological classification of grapevine phenology. Am J Enol Vitic 33:80-85.

21. Molitor D, Junk J, Evers D, Hoffmann L and Beyer M. 2014. A high-resolution cumulative degree day-based model to simulate phenological development of grapevine. Am J Enol Vitic 65:72-80.

22. Parker AK, De Cortázar-Atauri IG, Van Leeuwen $C$ and Chuine I. 2011. General phenological model to characterise the timing of flowering and veraison of Vitis vinifera L. Aust J Grape Wine Res 17:206-216.

23. Verdugo-Vásquez N, Pañitrur-De la Fuente C and OrtegaFarías S. 2017. Model development to predict phenological scale of table grapes (cvs. Thompson, Crimson and Superior Seedless and Red Globe) using growing degree days. OENO One 51:277-288.

24. Pratt C. 1971. Reproductive anatomy in cultivated grapes - A review. Am J Enol Vitic 22:92-109.

25. Zoecklein B, Fugelsang KC, Gump BH and Nury FS. 1999. Wine Analysis and Production. Aspen Publishers, New York. 